\title{
Novas espécies de Adetus (Coleoptera, Cerambycidae, Lamiinae, Apomecynini)
}

\author{
Ubirajara R. Martins ${ }^{1,3}$ \& Maria Helena M. Galileo ${ }^{2,3}$
}

1. Museu de Zoologia, Universidade de São Paulo, Caixa Postal 42494, 04218-970 São Paulo, SP, Brasil.

2. Museu de Ciências Naturais, Fundação Zoobotânica do Rio Grande do Sul, Caixa Postal 1188, 90001-970 Porto Alegre, RS, Brasil.

3. Bolsista do CNPq.

ABSTRACT. New species of Adetus (Coleoptera, Cerambycidae, Lamiinae, Apomecynini). The following species of Adetus LeConte, 1852 are described: from Bolivia (Santa Cruz), A. cacapira sp. nov. and A. cecamirim sp. nov.; from Peru (Cuzco), and Bolívia (Santa Cruz), A. inca sp. nov.; from Mexico (Veracruz), A. catemaco sp. nov.

KEYWORDS. Adetus, Bolivia, Mexico, Peru, taxonomy.

RESUMO. Trata-se da descrição de novas espécies de Adetus LeConte, 1852, provenientes da Bolívia (Santa Cruz): Adetus cacapira sp. nov. e A. cecamirim sp. nov.; do Peru (Cuzco) e da Bolívia (Santa Cruz): A. inca sp. nov. e do México (Veracruz): A. catemaco sp. nov.

PAlaVRaS-CHAVE. Adetus, Bolívia, México, Peru, taxonomia.

O gênero Adetus LeConte, 1852 reúne espécies que ocorrem desde os Estados Unidos até a Argentina. O gênero foi revisto por BREUNING (1971), que publicou chave para identificação das espécies, mas figurou apenas uma. Novas espécies foram incluídas no gênero, após aquela revisão, por LiNSLEY \& CHEMSAK (1984) e CHEMSAK \& Noguera (1993), Galileo \& Martins (2003a, 2003b, 2004) e por Martins \& Galileo (2003). Neste último trabalho foram propostas seis novas sinonímias, redescrita e figurada A. marmoratus Breuning, $1942 \mathrm{e}$ publicadas cinco espécies novas, principalmente do Brasil, todas ilustradas.

Objetiva-se tratar do material referente às espécies de Adetus enviado, para estudo, por J. E. Wappes (American Coleptera Museum, Bulverde, Texas, ACMB), que também reuniu espécimes do National Museum of Natural History, Washington (USNM) e da Florida State Collection of Arthropods, Gainesville (FSCA). Parte do material das espécies descritas foi retida para o Museu de Zoologia, Universidade de São Paulo, São Paulo (MZSP). J. E. Wappes e colaboradores estão realizando minucioso levantamento das espécies de Cerambycidae da Bolívia e eventuais holótipos devem ser depositados no Museu de Historia Natural Noel Kempff Mercado, Santa Cruz, Bolívia (MNKM).

\section{Adetus cacapira sp. nov.} (Fig. 1)

Etimologia. Tupi, çacapira = ponta, alusivo ao ápice dos élitros com mancha preta.

Tegumento castanho-avermelhado. Cabeça coberta por pubescência amarelada menos sobre os pontos, que são moderadamente densos. Lobos oculares inferiores com menos da metade do comprimento das genas. Antenas com tegumento castanho-avermelhado, mais escuro para o ápice. Antenas das fêmeas alcançam aproximadamente a metade dos élitros; nos machos, atingem o terço apical. Escapo com pubescência amarelada.

Lados do pronoto cobertos por pubescência amarelada, densa; disco com pontos grandes. Partes laterais do protórax com faixa de pubescência esparsa entre os lados do pronoto e o prosterno. Processo prosternal com carena centro-transversal. Processo mesosternal truncado anteriormente com gibosidade manifesta.

Metade anterior dos élitros com pequenas máculas de pubescência amarelada; no nível do terço posterior, mancha maior de pubescência amarelada; mancha apical preta bordejada por faixa de pubescência amarelada, precedida por um conjunto de manchas que se concentram em direção à faixa (fig. 1).

Mesepimeros, mesepisternos, metepisternos e lados do metasterno com pontos grossos entremeados por pubescência amarelada. Lados dos urosternitos I-IV com mancha glabra, preta bordejada por grumos de pubescência amarelada. Centro dos urosternitos com pubescência amarelada, esparsa, entremeada por pontos rasos e contrastantes. Fêmures com pubescência amarelada esparsa; principalmente os fêmures anteriores com pontos rasos e contrastantes. Tíbias dos machos levemente engrossadas.

Dimensões em $\mathrm{mm}$, respectivamente $0^{7} / \mathrm{q}$. Comprimento total, 10,9/11,9; comprimento do protórax, 2,4/2,7; maior largura do protórax, 2,9/3,2; comprimento do élitro, 8,4/8,6; largura umeral, 3,4/3,8.

Material-tipo. Holótipo ơ', BOLÍVIA, Santa Cruz: Buena Vista (4-6 km SSE, Hotel Flora \& Fauna), 27-29.X.2000, Wappes \& Morris col. (MNKM). Parátipos: ditto, duas + , 18-31.VII.2003, R. Clarke col. (MZSP, ACMB).

Discussão. Adetus cacapira sp. nov. pertence ao grande grupo de espécies com mancha de tegumento preto no ápice dos élitros e mesosterno projetado, mas difere de todas pelo aspecto da mancha amarelada do 
meio dos élitros, relativamente grande (fig. 1). Nas outras espécies a mancha do dorso dos élitros é apenas um pincel de pêlos como, por exemplo, em Adetus linsleyi Martins \& Galileo, 2003 (MARtins \& GALILEO, 2003: 377, fig. 4).

\section{Adetus cecamirim sp. nov.}

(Fig. 2)

Etimologia. Tupi, Cêcá $=$ olho, mirim $=$ pequeno, alusivo ao tamanho dos olhos.

Tegumento vermelho-acastanhado na cabeça, no pronoto e nos élitros. Élitros com áreas pretas (fig. 2): grande mancha circum-escutelar da base ao terço anterior, pequenas manchas ao redor dos pontos e região apical. Lado inferior do corpo e pernas castanho-avermelhados; centro do metasterno mais escuro.

Cabeça coberta por pubescência amarelada com pontos contrastantes, profundos na fronte e no vértice. Lobos oculares inferiores com um terço do comprimento das genas. Antenas atingem o meio dos élitros. Escapo com pubescência amarelada.

Pronoto revestido por pubescência amarelada mais adensada nos lados. Disco pronotal com alguns pontos grandes. Partes laterais do protórax com densa pubescência amarela. Processo prosternal com leve elevação transversal mediana. Processo mesosternal truncado anteriormente com gibosidade central manifesta. Pubescência elitral amarelada; pubescência branca: alguns pincéis na base; pequena mancha circular dorsal pouco atrás do meio; metade apical com raros pincéis mais concentrados numa faixa adiante da mancha apical, que é mais escura e recoberta por pubescência amarelada.

Mesepimeros, mesepisternos, metepimeros e metepisternos com pontos grossos acobertados pela pubescência amarelada. Lados do metasterno, dos urosternitos, fêmures e tíbias com pincéis de pubescência branca. Urosternitos II-V com manchas escuras laterais. Meso- e metatíbias engrossadas nos machos.

Dimensões em mm, respectivamente $\sigma^{2} /$. Comprimento total, 11,1-11,7/10,0; comprimento do protórax, 2,5-2,8/2,1; maior largura do protórax, 2,7-2,8/2,2; comprimento do élitro, $8,1-8,4 / 7,4$; largura umeral, 3,2-3,4/2,8.

Material-tipo. Holótipo ơ', BOLÍVIA, Santa Cruz: Buena Vista, 18-25.X.1992, E. Giesbert col. (FSCA). Parátipos: ditto (4-6 km SSE Hotel Flora \& Fauna), ơ, 23-26.X.2000, Wappes \& Morris col. (MZSP); ditto, 2 ㅇ, 1-8.XI.2002, J. E. Wappes col. (ACMB, MCNZ); ditto, , , 21-24.XI.2003, J. E. Wappes col. (ACMB); ditto, ○', 21-24.XI.2003, Wappes, Morris \& Nearns col. (ACMB).

Discussão. Adetus cecamirim sp. nov. caracterizase pelo conjunto de caracteres: mesosterno com tubérculo, pronoto coberto por pubescência amarelada (menos concentrada no meio); élitros com mancha dorsal branca pós-mediana, pincéis de pubescência branca junto à base e antes do ápice, faixa de pilosidade branca anteapical transversal, lado ventral do corpo e pernas com pincéis de pubescência branca.

\section{Adetus inca sp. nov.} (Fig. 3)

Etimologia. Epíteto alusivo ao país de procedência. Tegumento em geral avermelhado; antenas, face ventral do corpo e pernas, pretas. Cabeça coberta por pubescência amarelada adensada no vértice e mais esparsa na fronte e nas genas; pontuação contrastante, moderadamente densa e profunda. Lobos oculares inferiores com um terço do comprimento das genas. Antenas das fêmeas não atingem o meio dos élitros. Escapo revestido por escassa pubescência amarelada.

Lados do pronoto com faixa larga de pubescência amarelada densa. Disco pronotal com pontos grandes e profundos; pubescência esparsa. Partes laterais do protórax com faixa de pubescência esparsa na parte inferior. Processo prosternal com quilha transversal central. Processo mesosternal truncado anteriormente e com gibosidade.

Élitros recobertos por pubescência amarelada, mais esparsa no disco e adensada para os lados e em duas áreas (fig. 3): na mancha dorsal no terço posterior e na faixa anteapical larga que não toca a sutura. Tegumento elitral mais escuro entre as manchas e no ápice. Élitros densamente pontuados até a faixa apical; nos ápices, os pontos são muito rasos e pretos.

Mesosterno e metasterno com escassa pubescência amarelada. Lados do metasterno com pontos grandes. Lados dos urosternitos II-IV com áreas triangulares de pubescência amarelada que envolvem as manchas escuras; nos urosternitos as áreas amareladas têm pontos contrastantes. Fêmures com pubescência mais amarelada e abundantes pontos contrastantes.

Dimensões em mm, 9 . Comprimento total, 9,8-12,0; comprimento do protórax, 2,1-2,5; maior largura do protórax, 2,4-2,7; comprimento do élitro, 7,2-9,0; largura umeral, 3,0-3,4.

Material-tipo. Holótipo +, PERU, Cuzco: Pilcopata, 19.I.1979, W. E. Steiner col. (USNM). Parátipos: ㅇ, com os mesmos dados do holótipo (MZSP). Parátipos: BOLÍVIA, Santa Cruz: Achira (5400-5800 pés), ণ, 20.XI.2003, Wappes, Morris \& Nearns col. (MCNZ); ó, 2 9, 9-11.X.2004, Wappes \& Morris col. (ơn, MZSP; 2 \%, ACMB).

Discussão. Outra espécie descrita do Peru é $A$. albovittatus Breuning, 1966, que não conhecemos. Nesta espécie, os élitros apresentam uma larga faixa transversal pré-apical branca que descende obliquamente em direção à margem e uma faixa junto à borda lateral, atrás dos úmeros, curva-se fortemente para a sutura (não chega a atingi-la) e volta-se para a borda lateral, que alcança no terço apical. Em Adetus inca sp. nov., a metade anterior do élitro não possui faixa de pubescência branca. Também foram descritas do Peru, A. pacaruaia Martins \& Galileo, 2003 e A. pinima Martins \& Galileo, 2003. Ambas foram figuradas (Martins \& GaLILEO, 2003: 377, figs. 5, 6) e têm padrão de colorido dos élitros distinto.

\section{Adetus catemaco sp. nov.} (Fig. 4)

Etimologia. Epíteto alusivo à localidade-tipo.

Tegumento vermelho-acastanhado. Cabeça revestida por pubescência branco-amarelada com uma 

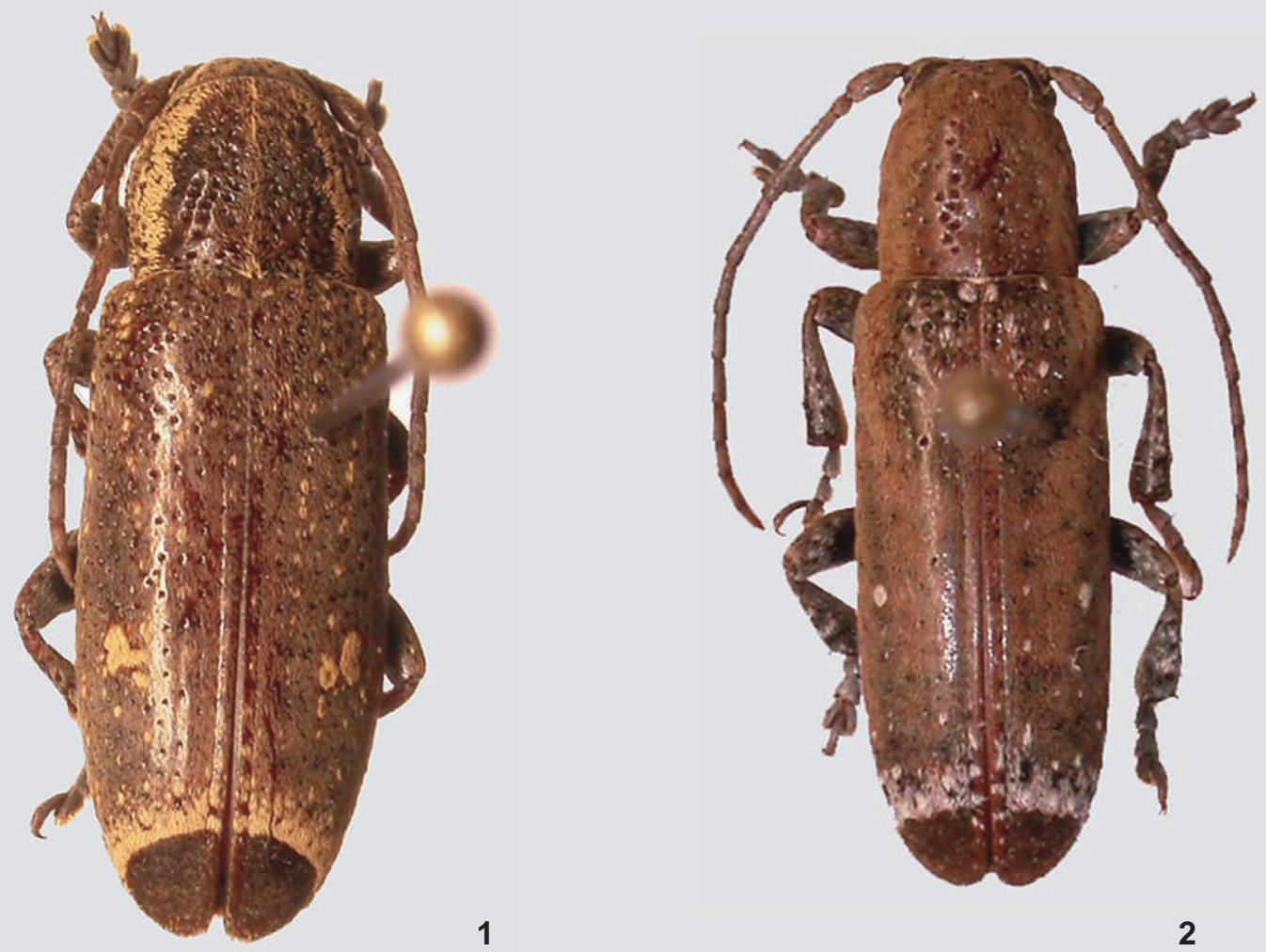

2
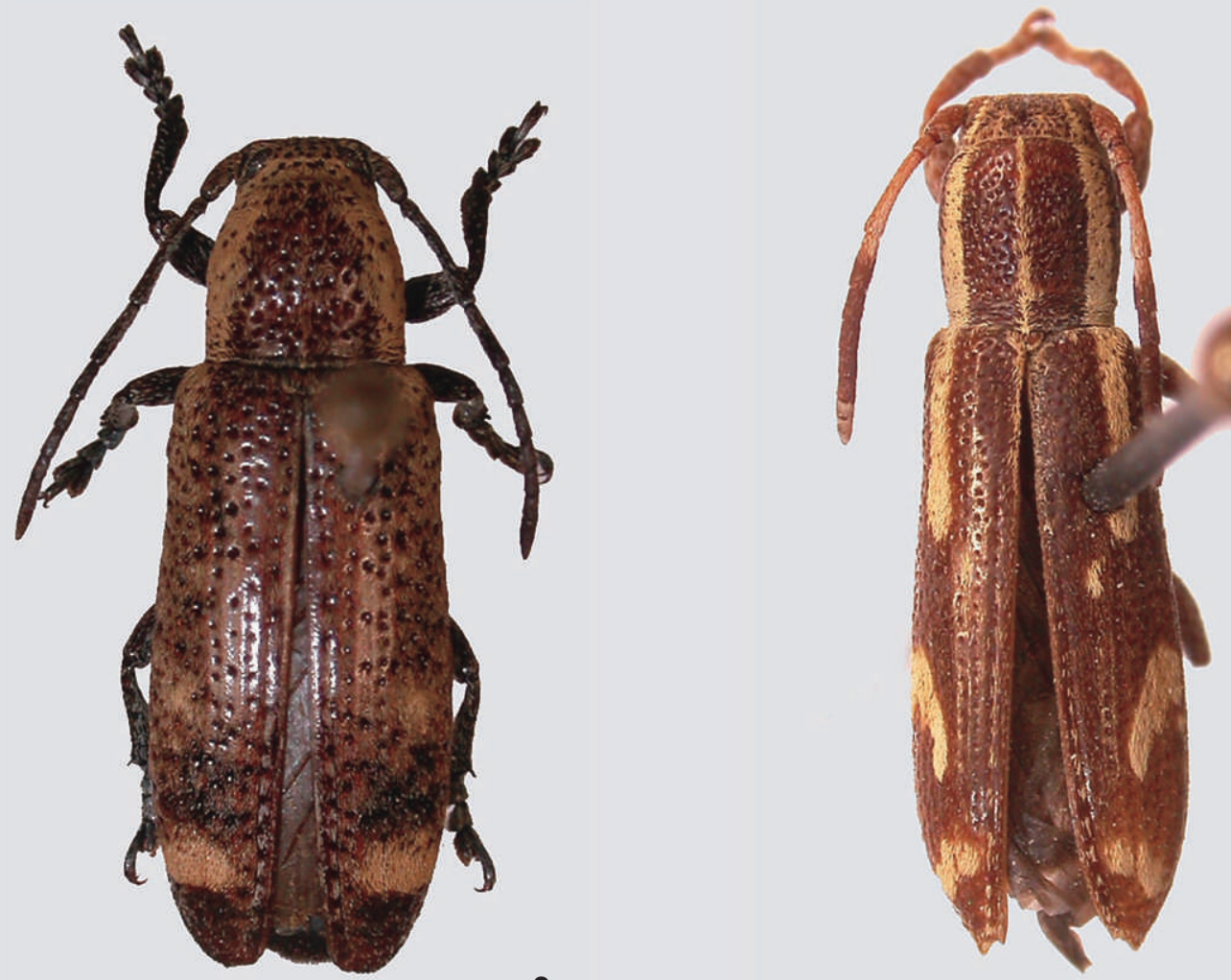

Figs. 1-4. Habitus. 1, Adetus cacapira sp. nov., holótipo ơ , comprimento $10,9 \mathrm{~mm} ; 2$, A. cecamirim sp. nov., holótipo $0^{\top}$, comprimento $11,1 \mathrm{~mm} ; 3$, A. inca sp. nov., holótipo + , comprimento $12,0 \mathrm{~mm} ; 4$, A. catemaco sp. nov., holótipo + , comprimento $8,7 \mathrm{~mm}$. 
faixa que se inicia entre os tubérculos anteníferos, passa pelo lobo interno dos lobos oculares superiores e termina no occipício; outra faixa transversal nas genas. Escapo, pedicelo, antenômero III e base do antenômero IV com tegumento avermelhado e pubescência branca. Antenômeros V-VIII pretos com pubescência preta; IX$\mathrm{XI}$ revestidos por pubescência branca. Antenas atingem o terço anterior dos élitros.

Pronoto com três faixas longitudinais de pubescência amarelada: uma no meio mais estreita e duas laterais largas; disco pontuado. Partes laterais do protórax com tegumento castanho-avermelhado, faixa longitudinal de pubescência branca em continuação à faixa genal, que segue pelo lado interno dos mesepisternos e lados do metasterno.

Élitros (fig. 4) com áreas de pubescência amarelada: faixa estreita, longitudinal no terço anterior (em continuação à faixa dos lados do pronoto); terço anterior do friso sutural; pequena mancha dorsal à frente do meio; mancha oblíqua, lateral, no terço apical, algo projetada para trás no lado externo; faixa anteapical oblíqua em sentido contrário. Extremidades dos élitros cortadas em curva com espinho no lado externo. Dorso da metade anterior dos élitros com pontos organizados em fileiras, bem visíveis no meio dos élitros. Pontuação elitral adensada para os lados. Face ventral coberta por pubescência esbranquiçada, esparsa entre as faixas laterais de pubescência branca densa. Urosternitos II -V com áreas laterais de pubescência branco-amarelada.

Dimensões em mm, o. Comprimento total, 8,7; comprimento do protórax, 1,9; maior largura do protórax, 1,9; comprimento do élitro, 6,4; largura umeral, 2,1 .

Material-tipo. Holótipo \&, MÉXICO, Veracruz: Coyame (Lago Catemaco), 1-15.VII.1963, D. R. Whitehead col. (USNM).
Discussão. Adetus catemaco sp. nov. assemelha-se a A. antennatus Thomson, 1868 e difere, principalmente, pelo aspecto da faixa de pubescência branca elitral em continuação com a do lado do pronoto. Em A. antennatus, a faixa anterior dos élitros é oblíqua em sentido descendente da margem para a sutura (BREUNING, 1971: 331, fig. 19).

Agradecimentos. A James E. Wappes (ACMB) pelo envio do material para estudo; a Rafael Santos de Araujo (MCNZ) pela execução das fotografias.

\section{REFERÊNCIAS BIBLIOGRÁFICAS}

Breuning, S. 1971. Révision des espèces américaines de la tribue des Apomecynini Lac. (Coleoptera, Cerambycidae). Entomologische Abhandlungen Staatliches Museum für Tierkunde in Dresden, 37(3):209-335.

Chemsak, J. A. \& Noguera, F. A. 1993. Annotated checklist of the Cerambycidae of the Estacion de Biologia Chamela, Jalisco, Mexico (Coleoptera), with descriptions of a new genera and species. Folia Entomologica Mexicana, 89:55-102.

Linsley, E. G. \& Chemsak, J. A. 1984. The Cerambycidae of North America. Part VII, No. 1. Taxonomy and classification of the subfamily Lamiinae, tribes Parmenini through Acanthoderini. University of California. Publications in Entomology, 102:ix $+258 \mathrm{p}$.

Galileo, M. H. M. \& Martins, U. R. 2003a. Cerambycidae (Coleoptera) da Colômbia. V. Lamiinae com unhas tarsais divergentes. Iheringia, Série Zoologia, 93(2):167-176.

2003b. Novas espécies e notas sobre Cerambycidae (Coleoptera) do Pará e do nordeste do Brasil. Revista Brasileira de Zoologia, 20(3):475-478.

2004. Novos táxons em Apomecynini (Coleoptera, Cerambycidae, Lamiinae) da Região Neotropical. Revista Brasileira de Entomologia, 48(1):55-57.

Martins, U. R. \& Galileo, M. H. M. 2003. Sinonímias e descrições em Adetus LeConte (Coleoptera, Cerambycidae, Lamiinae, Apomecynini). Entomologia, 47(3):373-378. 